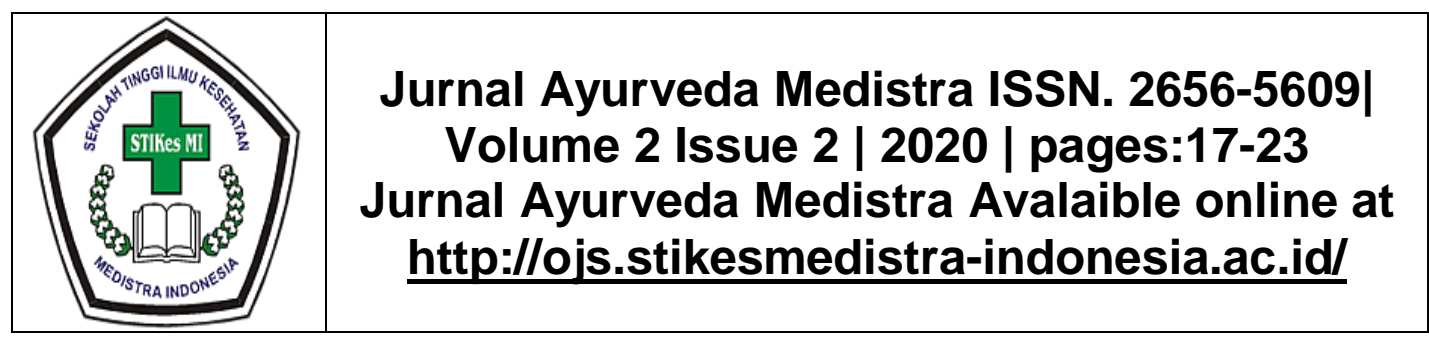

\title{
HUBUNGAN PARITAS DENGAN KEJADIAN PLASENTA PREVIA DI RSUD DR. CHASBULLAH ABDULMADJID KOTA BEKASI TAHUN 2018
}

\author{
Rupdi Lumban Siantar ${ }^{1}$, Alviani Cahya Lestari ${ }^{2}$ \\ 1Program Studi Kebidanan (D3) STIKes Medistra Indonesia Rupdie63@yahoo.co.id \\ 0812-8818-5648 \\ 2Program Studi Kebidanan (D3) STIKes Medistra Indonesia \\ alvianicahyalestari2@gmail.com 0857-8128-3858
}

\begin{abstract}
Abstrak
Parity is the number of deliveries a mother has experienced, both live and stillbirth. Parity is divided into 3, namely: a) Primipara: a woman who has given birth once to a baby who has reached the stage of being able to live. b) Multipara: woman who has given birth to two or more fetuses. c) Grandemultipara: woman who has given birth to five or more children. In multiparous women placenta previa often occurs. In multipara placenta previa occurs due to reduced vascularization and atrophy in the decidua caused by previous labor which can cause the placenta to expand its surface and close the birth canal.

To find out the relationship between parity and the incidence of placenta previa in RSUD dr. Chasbullah Abdulmadjid Bekasi City in 2018.

This type of research is cross sectional. The population in this study was maternity mothers who experienced placenta previa in RSUD dr. Chasbullah Abdulmadjid Bekasi City in 2018. The method used is Probability sampling with Simple Random Sampling technique and using the Slovin formula.

Statistical test results obtained $p=0,001 \quad(p<0,05)$ which means that there is a relationship between parity and the incidence of placenta previa.

Conclusion: There is a Parity Relationship with the Occurrence of Placenta Previa in Dr.Chasbullah Abdulmadjid Regional Hospital, Bekasi City in 2018.

Keywords : Parity and placenta previa
\end{abstract}

\begin{abstract}
Abstrak
Paritas merupakan jumlah persalinan yang pernah dialami ibu baik lahir hidup maupun lahir mati. Paritas dibagi menjadi 3 yaitu : a) Primipara: wanita yang pernah satu kali melahirkan bayi yang telah mencapai tahap mampu hidup. b) Multipara: wanita yang telah melahirkan dua janin atau lebih. c) Grandemultipara: wanita yang telah melahirkan lima anak atau lebih. Pada wanita multipara sering terjadi plasenta previa.Pada multipara plasenta previa terjadi karena vaskularisasi yang berkurang dan atrofi pada desidua yang disebabkan persalinan sebelumnya yang dapat menyebabkan plasenta memperluas permukaannya dan menutup jalan lahir.Mengetahui Hubungan Paritas Dengan Kejadian Plasenta Previa Di RSUD dr. Chasbullah Abdulmadjid Kota Bekasi Tahun 2018.
\end{abstract}


Jenis penelitian ini adalah cross sectional. Populasi dalam penelitian ini adalah ibu bersalin yang mengalami plasenta previa Di RSUD dr. Chasbullah Abdulmadjid Kota Bekasi Tahun 2018. Metode yang digunakan adalah Probability samplingdengan teknik SimpleRandom Sampling dan menggunakan rumus slovin.

Hasil uji statistik didapatkan nilai $p=0,001(p<0,05)$ yang artinya bahwaada hubungan paritas dengan kejadian plasenta previa.

Ada Hubungan Paritas Dengan Kejadian Plasenta Previa Di RSUD dr.Chasbullah Abdulmadjid Kota Bekasi Tahun 2018.

Kata kunci $\quad$ : Paritas dan plasenta previa

\section{PENDAHULUAN}

Paritas merupakan jumlah persalinan yang pernah dialami ibu baik lahir hidup maupun lahir mati. Dalam jurnal wahyu utami ekasari( 2015 ) Jenis paritas bagi ibu yang sudah partus antara lain yaitu : a) Primipara adalah wanita yang pernah satu kali melahirkan bayi yang telah mencapai tahap mampu hidup; b) Multipara adalah wanita yang telah melahirkan dua janin atau lebih; c) Grandemultipara adalah wanita yang telah melahirkan lima anak atau lebih. Pada seorang grande multipara biasanya lebih banyak penyulit dalam kehamilan dan persalinan. (Prawiroharjo, 2012).

Pada wanita multipara sering terjadi plasenta previa.(Sukrisno A, 2010). Pada multipara plasenta previa terjadi karena vaskularisasi yang berkurang dan atrofi pada desidua yang disebabkan persalinan sebelumnya yang dapat menyebabkan plasenta memperluas permukaannya dan menutup jalan lahir. (Abdat AU, 2010 dalam jurnal Mustika ratnaningsih Purbowati 2017).

Hal ini sesuai dengan teori Summapraja (2011) yang mengatakan wanita multipara 3 kali lebih sering terjadi plasenta previa dari pada primipara. Paritas lebih dari satu mempertinggi risiko terjadinya placenta previa karena dalam kehamilan placenta mencari tempat yang paling subur untuk berimplantasi. Pada kehamilan pertama fundus merupakan tempat yang subur dan tempat favorit untuk plasenta berimplantasi, tetapi seiring bertambahnya frekuensi kehamilan kesuburan pada fundus akan semakin berkurang. Hal itu mengakibatkan placenta mencari tempat lain untuk berimplantasi dan cenderung ke bagian bawah Rahim. (Indah Trianingsih2015).

Komplikasi plasenta previa dimana plasenta terletak di bagian bawah rahim, sebagian atau seluruhnya menutupi leher rahim. Hal ini menyebabkan perdarahan vagina tanpa rasa sakit dan beberapa mengarah ke perdarahan. Perdarahan yang mungkin cukup besar untuk mengancam kehidupan ibu dan janin membuat persalinan segera. (Alif A. Pawadkk 2015).

$\mathrm{Di}$ indonesia penyebab kematian ibu terbanyak yang disebabka karna perdarahan obstetric. Dinas Kesehatan Jawa Barat, penyebab kematian ibu hamil di provinsi Jawa Barat akibat perdarahan sebesar 58,79\%.5 Perdarahan sebagai penyebab kematian ibu terdiri atas perdarahan antepartum dan postpartum. Berdasarkan sumber Ditjen Bina Gizi dan KIA, Kemenkes RI 2014 mencatat penyebab kematian ibu yang disebabkan oleh perdarahan $(30,3 \%)$, hipertensi dalam kehamilan $(27,1 \%)$, infeksi $(7,3 \%)$, partus lama $(0 \%)$ dan abortus (0\%). Selain penyebab obstetrik, 
kematian ibu juga disebabkan oleh penyebab lain-lain (non obstetrik) sebesar 40,8\%. Perdarahan dalam obstetri dapat terjadi pada setiap usia kehamilan. Perdarahan antepartum merupakan kasus gawat darurat yangkejadiannya berkisar $3 \%$ dari semua persalinan, penyebabnya antara lain plasenta previa, solusio plasenta, dan perdarahan yang belum jelas sumbernya.1 Dari seluruh kasus perdarahan antepartum, plasenta previa merupakan penyebab utama.Meskipun plasenta previa relatif jarang, tetapi hal tersebut dianggap sebagai salahsatu faktor utama terjadinya perdarahan yang dapat menyebabkan masalah yang serius baik untuk ibu ataupun bayi itu sendiri, dengan meningkatnya risiko kematian ibu dan bayi, gangguan tumbuh bayi, kelahiran kurang bulan, perlunya transfusi darah, dan juga histerektomi. (Chalik,2010; Departemen Kementerian Kesehatan RI, 2015).

Berdasarkan hasil studi pendahuluan yang dilakukan diruang ponek dan ruang dahlia di RSUD dr. Chasbullah Abdulmadjid Kota Bekasi periode Januari - Desember 2018 didapatkan jumlah kasus plasenta previa yang bersalin sebanyak 85 kasus.

\section{Tujuan}

tujuan penelitian ini untuk Mengetahui

\begin{tabular}{ccc}
\hline Paritas & Frekuensi & Presentase(\%) \\
\hline $\begin{array}{c}\text { Primipara } \\
\text { (1Anak) }\end{array}$ & 61 & 43.6 \\
$\begin{array}{c}\text { Multipara (>2 } \\
\text { Anak) } \\
\text { Grandemultipara } \\
(>\mathbf{5})\end{array}$ & 73 & 52.1 \\
Jumlah & 140 & 4.3 \\
\hline
\end{tabular}

Hubungan Paritas Dengan Kejadian Plasenta Previa Di RSUD dr. Chasbullah Abdulmadjid Kota Bekasi Tahun 2018.

\section{METODE PENELITIAN}

Jenis Penelitian ini merupakan studi analitik. Penelitian ini bersifat kuantitatif yang menggunakan data skunder dengan studi cross sectional. Penelitian ini dilaksanakan di RSUD dr. Chasbullah Abdulmadjid Kota Bekasi Tahun 2018. Populasi yang digunakan dalam penelitian ini adalah ibu bersalin yang mengalami plasenta previa Di RSUD dr. Chasbullah Abdulmadjid Kota Bekasi Tahun 2018. Sampel yang digunakan dalam penelitian ini adalah ibu bersalin yang mengalami plasenta previa. rumus yang digunakan untuk menghitung sample adalah rumus slovin.

\section{ANALISIS DATA}

Hasil analisis sementara penelitian ini adalah membandingkan hasil presentase secara kuantitatif, untuk menghitung besarnya korelasi digunakan tehnik statistic analisa korelasi kontigensi table $3 \times 2$, koefisien korelasi adalah indeks atau bilangan yang digunakan untuk mengukur derajat hubungan dan bentuk dan arah hubungan (hasan 2004 : 44). Dengan Uji Z score dari frank Wilcoxon menggunakan SPSS 10.0

HASIL PENELITIAN

\section{Analisi Univariat}

Tabel 1

Distribusi ibu bersalin berdasarkan paritasdi RSUD dr. Chasbullah Abdulmadjid Kota

Bekasi 2018 


\section{Analisi bivariate}

Berdasarkan table 1 Dari 140 ibu bersalin diketahui, bahwa lebih banyak ibu bersalin dengan paritas multipara sebesar $73(52.1 \%)$, dibandingkan dengan ibu bersalin primipara sebesar 61 (43.6\%), dan lebih kecil pada ibu bersalin yang grandemultipara sebesar 6 (4.3\%).

Tabel 2

Distribusi ibu bersalin berdasarkan plasenta previa di RSUD dr. Chasbullah Abdulmadjid

\begin{tabular}{ccc}
\hline $\begin{array}{c}\text { Plasenta } \\
\text { Previa }\end{array}$ & Frekuensi & Presentase \\
\hline Ya & 84 & 60.0 \\
Tidak & 56 & 40.0 \\
Jumlah & 140 & 100.0 \\
\hline
\end{tabular}

Kota Bekasi 2018

Berdasarkan table 2 Dari 140 ibu bersalindiketahui,bahwa lebih banyak ibu bersalin yang mengalami plasenta previa sebesar $84(60.0 \%)$ dibandingkan dengan ibu bersalin yang tidak mengalami plasenta previa yaitu sebesar (40.0\%).
Tabel 3

Hubungan Paritas dengan kejadian Plasenta Previa pada ibu bersalindi RSUD dr. Chasbullah Abdulmadjid Kota Bekasi tahun 2018.

\begin{tabular}{|c|c|c|c|c|c|c|c|}
\hline \multirow[t]{3}{*}{ Paritas } & \multicolumn{4}{|c|}{ Plasenta previa } & \multirow{2}{*}{\multicolumn{2}{|c|}{ Total }} & \multirow[t]{3}{*}{ Pvalue } \\
\hline & \multicolumn{2}{|l|}{$\mathrm{Ya}$} & \multicolumn{2}{|c|}{ Tidak } & & & \\
\hline & $\mathrm{N}$ & $\%$ & $\mathrm{~N}$ & $\%$ & $\mathrm{~N}$ & $\%$ & \\
\hline Primi & 15 & $24.6 \%$ & 46 & $75.4 \%$ & 61 & $100.0 \%$ & 0,001 \\
\hline Multi & 63 & $86.3 \%$ & 10 & $13.7 \%$ & 73 & $100.0 \%$ & \\
\hline Grande & 4 & $66,7 \%$ & 2 & $33.3 \%$ & 6 & $100.0 \%$ & \\
\hline Total & 82 & $58.6 \%$ & 58 & $41.4 \%$ & 140 & $100.0 \%$ & \\
\hline
\end{tabular}

Hasil analisis hubungan paritas dengan kejadian plasenta previa diketahui bahwa lebih banyak ibu bersalin multipara sebesar 63 (86.3\%), dibandingkan dengan ibu bersalin primipara sebesar 15 (24.6\%), dan lebih kecil pada ibu bersalin yang grandemultipara sebesar $4(66,7 \%)$.

Hasil uji statistik didapatkan nilai $\mathrm{p}=$ $0,001(p<0,05) \quad$ yang artinya bahwaada hubungan paritas dengan kejadian plasenta previa.

\section{PEMBAHASAN}

ParitasPenelitian paritas pada ibu bersalin diketahui,bahwa lebih banyak ibu bersalin dengan paritas multipara sebesar 73 (52.1\%), dibandingkan dengan ibu bersalin primipara sebesar 61 (43.6\%), dan lebih kecil pada ibu bersalin yang grandemultipara sebesar $6(4.3 \%)$.

Dirumah sakit RSUD Kota Bekasi pada tahun 2017 didapatkan ibu bersalin dengan 
riwayat paritas sebesar 520 orang mengalami penurunan pada tahun 2018 sebesar 140 orang. Karna adanya program kelarga berencana dan seringnya mendapatkan pendidikan kesehatan.

Hasil penelitian Abdat (2010) menemukan bahwa ibu dengan paritas $\geq 3$ memiliki risiko mengalami plasenta previa dibandingkan ibu dengan paritas 1-2. Meningkatnya risiko pada multiparitas adalah disebabkan karena vaskularisasi dsidua yang jelek akibat persalinan yang berulang-ulang sehingga menyebabkan endometrium cacat, dan aliran darah ke plasenta tidak cukup sehingga plasenta memperluas permukaannya untuk mencari bagian dengan suplai darah yang banyakyaitu bagian segmen bawah uterus dan menutupi jalan lahir, yangbiasanya dikaitkan dengan placenta migration (Hartono, 2011).

\section{Plasenta previa}

Pada penelitian ini diketahui,bahwa lebih banyak ibu bersalin yang mengalami plasenta previa sebesar $84 \quad(60.0 \quad \%)$ dibandingkan dengan ibu bersalin yang tidak mengalami plasenta previa sebesar 56 (40.0\%).

Dirumah sakit RSUD Kota Bekasi pada tahun 2017 didapatkan ibu bersalin dengan riwayat plasenta previa sebesar 108 orang mengalami penurunan pada tahun 2018 sebesar 85 orang.

Plasenta previa yang berimplantasi pada bagian segmen bawah rahim, sehingga dapat menutupi sebagian atau seluruh jalan lahir yang ditandai dengan perdarahan uterus.Faktor risiko timbulnya plasenta previa belum diketahuisecara pasti namun dari beberapa penelitian dilaporkan bahwafrekuensi plasenta previa tertinggi terjadi pada ibu yang berusia lanjut,multipara, riwayat seksiosesar dan aborsi sebelumnya serta gaya hidup yang juga dapat mempengaruhi peningkatan resiko terjadi plesenta previa(Cut Meurah Yeni,dkk 2017).

Penyebab plasenta previa pada ibu hamil juga ditandai dengan bertambahnya usia kehamilan, segmen bawah uterus akan lebih melebar dan serviks mulai membuka. Apabila plasenta tumbuh pada segmen bawah uterus, pelebaran segmen bawah uterus dan pembukaan serviks tidak dapat diikuti oleh plasenta yang melekat didinding rahim sehingga plasenta berada dibawah yang menutupi sebagian atau seluruh jalan lahir, semakin rendah letak plasenta maka semakin dini terjadinya perdarahan. (Fauziyah, 2016). Perdarahan biasanya terjadi pada kehamilan lanjut trimester ketiga (III) atau pada usia kehamilan 28 minggu. Pada kasus plasenta previa terjadi pada kehamilan Trimester III dengan usia 28 minggu. (Tyagi, dkk. 2016).

\section{Hubungan paritas dengan kejadian plasenta previa}

Hasil analisis hubungan paritas dengan kejadian plasenta previa diketahui bahwa ibu bersalin yang mengalami plasenta previa lebih banyak ibu bersalin multipara sebesar 63 (86.3\%), dibandingkan dengan ibu bersalin primipara sebesar 15 (24.6\%), dan lebih kecil pada ibu bersalin yang grandemultipara sebesar $4(66,7 \%)$.

Dirumah sakit RSUD Kota Bekasi pada tahun 2017 didapatkan ibu bersalin dengan 
riwayat paritas dengan kejadian plasenta previa sebesar 108 orang mengalami penurunan pada tahun 2018 sebesar 85 orang. Karna sudah berjalannya program KB.

Hal ini sesuai kasus kejadian Plasenta Previaterjadi pada multiparitas Wardana dan Karkata (2007) yang menyatakan bahwa kejadian Plasenta Previa terjadi karena jaringan parut rahim pada kehamilan berulang mengakibatkan rusaknya jaringan yang digunakan sebagai tempat implantasi. Jaringan yang rusak inilah dapat memberikan resiko uterus menjadi renggang sehingga dapat menyebabkan kelainan letak dan kelainan pada plasenta. yang dapat menyebabkan terjadinya kejadian Plasenta Previa, sehingga diperlukan persalinan dengan Sectio Cesarea.

Kemudian, frekuensi Plasenta Previalebih banyak terjadi pada ibu hamil dengan di bawah 20 tahun atau di atas 35 tahun. Hasil penelitian menunjukkan bahwa dari subyek penelitian, sebagian besar berasal dari kelompok usia diatas 35 tahun. Kecenderungan ini terjadi karena pada ibu hamil usia diatas 35 tahun memiliki penurunan fungsi organ tubuh, terutama organ reproduksi, sehingga endometrium kurang subur, yang menyebabkan aliran darah tidak merata. Hal serupa juga terjadi pada ibu hamil usia dibawah 20 tahun karena belum sempurnanya pertumbuhan endometrium sehingga belum berfungsi secara normal.

\section{KESIMPULAN}

Dari hasil penelitian mengenai hubungan paritas dengan kejadian plasenta previa di RSUD dr. Chasbullah Abdulmadjid Kota Bekasi Tahun 2018, diperoleh kesimpulan
Bahwa lebih banyak ibu bersalin dengan paritas multipara sebesar 73 (52.1\%), dibandingkan dengan ibu bersalin primipara sebesar 61 (43.6\%), dan lebih kecil pada ibu bersalin yang grandemultipara sebesar 6 (4.3\%). Dan lebih banyak ibu bersalin yang mengalami plasenta previa sebanyak 84 (60.0\%) dibandingkan dengan ibu bersalin yang tidak mengalami plasenta previa yaitu 56 (40.0 \%). Ada hubungan paritas dengan kejadian plasenta previa di RSUD dr. Chasbullah Abdulmadjid Kota Bekasi, dengan Hasil uji statistik, chi square didapatkan nilai $p=0,001(p<0,05)$.

\section{DAFTAR PUSTAKA}

1. Alfika Safitri; Gejala Plasenta Previa (2014)

2. Alif A.Pawa., Komplikasi Pasenta, Perdarahan Pervaginam, (2015)

3. Anisafitri, (2010). Hubungan Usia Ibu Dengan Kejadian Perdarahan Antepartum.

4. Bakker, patofisiologi plasenta previa (2018)

5. Chalik, 2010; Departement Kementrian Kesehatan RI (2015).

6. Creasy RK, Resnik R, lams J, Lockwood C, Moore T, Greene M. Placenta Previa, Placenta Accreta, Abruptio Placentae And Vasa Previa.Creasy And Resnik's Maternal Fetal Medicine : Principles And Practice. Ed 7th.Saunders : Philadelphia, PA ; 2014. 732-742.

7. Cut meurah yeni dkk definisi plasenta , pemeriksaan perdarahan, asuhan kebidanan (2017) 
8. Fauziah Yulia. Obstetric Patologi Untuk Mahasiswa Kebidanan Dan Keperawatan. Yogakarta, Nuhu Medika,2016.

9. Maryuni, Anik. Buku Praktis Kehamilan Dan Persalinan Patologis Dalam Kebidanan.Jakarta CV Trans Info Media.2016.

10. Masruroh. Buku Ajar Kegawat Daruratan Maternal Neonatal.Yogyakarta Parama Publishing, 2016.

11. Maulidan Fa,Daud Sr, Rahardiyanto Ky2013. Karakteristik Plasenta Previa Data Rekam Medic Pada Ibu Melahirkan Dirsud Palembang Bari :2013,Sep $4(1): 48-56$.

12. Nicholson et al.,(2006);agrawal et al., pengaruh paritas terhadap ibu hamil, asuhan kebidanan (2011)

13. Prawirdjo, Sarwono, IImu Kebidanan,Jakarta Kdt;2014 Shrestha
Sarada D, Dkk. Antepartum Hemmorage At A Tertiary Care Teaching Hospitalin Nopal. Journal Of Patan Academy Of Health Sciences.2017 Dec;2 (2):44-80.

14. Sugiyono. 2014. Metode Penelitian Kuantitatif, Kualitatif, Dan Kombinasi (Mixed Methode). Bandung: Alfabeta.

15. Tammy febriani, langkah pertolongan darurat, 2015.

16. Trianingsih Indah, Mardhiya Dian, Duarsa Ab. Factor-Faktor Yang Berpengaruhpada Timbulnya Kejadian Plasenta Previa. Jurnal Kedokteran Yarsi. 23 (2) : 103-13 (2015).

17. Word Healthy Organization (2016).Maternal Mortality (Diunduh 12 Febriari 2018).

18. Wiknjosastro (2013) multiparitas plasenta previa 2013. 